\title{
Isolation and characterization of lignin from okra (Abelmoschus esculentus) fibre and stick
}

\author{
M. Sarwar Jahan ${ }^{1 *}$, D. Alam ${ }^{2}$, M. Mostafzur Rahman ${ }^{1}$ and M. A. Quaiyyum ${ }^{2}$ \\ ${ }^{1}$ Pulp and Paper Research Division, BCSIR Laboratories, Dhaka, Dr. Qudrat-i-Khuda Road, Dhaka 1205, Bangladesh. \\ ${ }^{I}$ Department of Applied Chemistry and Chemical Engineering, University of Dhaka, Dhaka 1000, Bangladesh.
}

\begin{abstract}
The okra (Abelmoschus esculentus) plant consists of bast fiber and core (stick). The bast fibre of okra plant was characterized with high $\alpha$-cellulose (56.7\%) and low lignin (12.6\%) and stick withlow $\alpha$-cellulose (34.3\%) and high lignin (25.2\%) content. Lignin was isolated from the fiber and stick by acidolytic dioxane method and characterized for elemental analysis, methoxyl analysis and FTIR and ${ }^{1} \mathrm{H}-\mathrm{NMR}$ spectroscopy. The $\mathrm{C}_{9}$ formulas for okra stick and fibre lignin were $\mathrm{C}_{9} \mathrm{H}_{9 \cdot 61} \mathrm{O}_{4.63}\left(\mathrm{OCH}_{3}\right)_{1.24}$ and $\mathrm{C}_{9} \mathrm{H}_{8.61} \mathrm{O}_{4.66}\left(\mathrm{OCH}_{3}\right)_{1.49}$, respectively. Both of the lignins were of the guaiacyl-syringyl type. The bands of FT-IR spectrum at $1327 \mathrm{~cm}^{-1}, 1122 \mathrm{~cm}_{-}{ }^{1}$ and $837 \mathrm{~cm}-{ }^{1}$ associated with syringyl unit was higher in okra fibre lignin than in the okra stick lignin. The structural analysis revealed that the average numbers of proton of $\beta-O-4$ $(\mathrm{H} \alpha \& \mathrm{H} \beta)$ per $\mathrm{C}_{9}$ unit in okra stick and fibre lignin were 1.53 and 1.20 , respectively. The $\beta-O-4$ units in these lignins had predominately erythro stereochemistry type.
\end{abstract}

Keywords: Okra plant; Fibre and stick; Dioxane lignin; Syringyl unit; Guaiacyl unit; Erythro type

\section{Introduction}

Over the last few years, forest preservation and rational use of forest and agricultural residues has received attraction. The world consumption of paper, especially fine paper is expected to increase, which indicates increased demand of fibre. Traditionally, hardwood meets the demand for short fibre in fine paper production. The wood is being gradually replaced by nonwood; although about $10 \%$ of the world's overall pulp is obtained from nonwood. In many countries, like Bangladesh, the wood supplies availability will not continue to meet the rising demand for fibre. Research shows that agricultural wastes could be a potential source of fibre for papermaking. Okra plant (Abelmoschus esculentus) is one of the major vegetable wastes in Bangladesh which is an annual or perennial plant of about $2 \mathrm{~m}$ tall. Abelmoschus esculentus is cultivated throughout the tropical and warm temperate regions of the world for its fibrous fruits consumed as vegetables. Okra plant consists of short fiber stick and long bast fibre like jute plant (Jahan et al., 2008). Chemical characteristics of this plant have been presented in another article (Jahan et al., 2012). The holocelluose and $\alpha$-cellulose content are higher and lignin content is lower in the bast fibre than that of stick. The $\alpha$-cellulose content in bast fibre is $56.7 \%$ while stick contains as little as $34.4 \%$. The lignin content in the bast fibre is similar to jute fibre (Jahan et al., 2007), while lignin present in the okra stick is similar to hardwoods. In order to use the agricultural waste as pulping feedstock, it is needed to characterize the raw material, and also to gain knowledge of delignification and characteristics of its lignin. Isolation and characterization of lignin from lignocelluloses is a fundamental step for investigations of suitable pulping process and conditions. Lignin offers significant opportunity and presents many challenges for enhancing the operation of a lignocellulosic biorefinery. Lignin is a promising feedstock for generating renewable substitutes for fossil fuel.

Lignin is a heterogeneous and highly cross-linked macromolecule that represents the second most abundant natural polymeric material on earth (Fengel and Wegener, 1989). It is known that the most of the lignin in lignocelluloses consists of nonphenolic aryl-glycerol-b-O-aryl ether units. Other units, such as phenylcoumaran (b-5), resinol (b-b), and dibenzodioxocins $(5-5 / b-O-4, \alpha-O-4)$ are also present within the lignin macromolecule (Fengel and Wegener 1989; Ralph et al., 2000). Furthermore, lignin is covalently linked to carbohydrates forming a lignin-carbohydrate network made 
up of benzyl-ether (Eriksson et al., 1980; Lowoko et al., 2003; Yaku et al., 1981), benzyl-ester (Eriksson et al., 1980), and phenyl-glycoside (Yaku et al., 1976) bonds. The characteristics of lignin obtained from biomass depend on both the kind of species, location and on the types. Still there is no perfect technique that would provide extraction of high lignin yield without chemical modification, and recovery of pure product (Tamminen and Hortling, 1999). A great variation is observed in various species in regards to ultimate analysis, methoxyl and hydroxyl content as well as syringyl-guaiacyl ratio. The major problem of elucidating lignin structure is total isolation of lignin in unaltered form. Björkman developed a method known as "milled wood lignin (MWL)" for the isolation of lignin by neutral solvent at room temperature, which is considered as unaltered lignin. But the yield is less, certainly does not represent whole lignin (Björkman, 1957). Acidic dioxane methods give much better yield than MWL (Tamminen and Hortling, 1999), although this method may alter lignin structure due to acidic condition. Therefore, the main objectives of this study were to isolate lignin by dioxane/ $\mathrm{HCl}$ mixture from the okra stick and bast fibre, and the isolated lignin characterized by elemental, methoxyl, FTIR and ${ }^{1} \mathrm{H}-\mathrm{NMR}$ spectroscopy.

\section{Materials and methods}

\section{Materials}

A farmer supplied okra plants after harvesting the crop in the region of Savar, Dhaka. Subsequently, okra plant was retted for a month and the fibre and stick separated. Afterwards, these were properly sun dried. The stick and fibre were separately ground in a Willey Mill and screened to 40/60 mesh for lignin isolation.

\section{Isolation of lignin}

Okra stick and fibre meals (40-60 mesh) were refluxed with acetone solvent for $12 \mathrm{~h}$. The acetone extractive free meals were refluxed with acidic dioxane (9:1) solution. The concentration of $\mathrm{HCl}$ in dioxane solution was $0.2 \mathrm{~N}$. The dioxane to meal ratio was $8: 1$. The meal was refluxed with dioxane solution for $1 h$ at $\mathrm{N}_{2}$ atm. The $\mathrm{N}_{2}$ flow was maintained at $50 \mathrm{ml} / \mathrm{min}$. After completing reflux time, wood meal dioxane mixture was filtered in a Buckner funnel using Whatmann filter paper no. 2. The residue was washed with dioxane solution. The filtrate was concentrated in a vacuum evaporator at $40^{\circ} \mathrm{C}$. Then conc. dioxane soln. was added drop wise to deionized water to precipitate lignin. Precipitated lignin was centrifuged and washed frequently until reaching $\mathrm{pH}$ around 7 and dried. Dried crude lignin was dissolved in dioxane (9:1), and again precipitated in ether with constant stirring by magnetic bar. The precipitated lignin was dried under vacuum over $\mathrm{P}_{2} \mathrm{O}_{5}$ and weighed.

\section{Acetylation of lignin}

A mixture of $100 \mathrm{mg}$ purified lignin and $1.5 \mathrm{ml}$ pyridineacetic anhydride (1:1) was kept for $72 \mathrm{~h}$ with frequent stirring. The solution was added to a 10 -fold volume of ice-cold water whereupon the acetylated sample was recovered as a precipitate, which was purified by successive washing with water and dried in vacuum desiccators over $\mathrm{P}_{2} \mathrm{O}_{5}$.

\section{Elemental analysis}

Analysis of $\mathrm{C}$ and $\mathrm{H}$ in okra stick and fibre lignin was carried out by Analytical Research Division of BCSIR Laboratories, Dhaka, and the oxygen was determined by difference. The methoxyl content in lignin was determined in accordance to Japan International Standard Methods (JIS P8013 1972).

\section{Spectroscopy}

FTIR: Infrared spectra were recorded by using a Shimadzu FTIR spectrometer model 8201PC.The dried samples were embedded in $\mathrm{KBr}$ pellets in the concentration of about $1 \mathrm{~m}$ $\mathrm{g} / 100 \mathrm{mg} \mathrm{KBr}$. The spectra were recorded in the absorption band mode in the range 4000-400 $\mathrm{cm}^{-1}{ }^{1} \mathrm{H}$ NMR: Spectra of lignin samples (100 mg of acetylated lignin contained in 0.5 $\mathrm{ml} \mathrm{CDCl}_{3}$ ) were recorded in a Bruker 400 spectrometer. $\mathrm{CDCl}_{3}$ solvent was used as internal standard (ppm 7.25). For quantification of protons, the signal in specified region of the spectrum was integrated with respect to a spectrum-wide baseline drawn at the level of the background noise, and the results were referred to the signal for methoxyl protons. The average number per $\mathrm{C}_{9}$ unit was established as described above.

\section{Results and discussion}

The yield of dioxane lignin from okra fibre was $70.5 \%$ and stick 68.7\%, (Table I). The acidic isolation conditions employed for the lignin extraction process may be the result of the hydrolysis of lignin-carbohydrate complex (LCC) linkages allowing the release of lignin fragments into the aqueous dioxane solution from the okra fibre and stick (Gellerstedt et al., 1994).

\section{Table I. Yields of lignin}

\begin{tabular}{lc}
\hline Sample & Lignin yield, \% ( based on Klason lignin) \\
\hline Okra stick & 68.7 \\
Bast fibre & 70.5 \\
\hline
\end{tabular}




\section{Elemental analysis and $C_{9}$ formula}

Table II. shows the elemental analysis, methoxyl content, and their average $\mathrm{C}_{9}$ units as calculated from these analytical data for the lignin. Since lignin always contains associated carbohydrates and impurities, the average $\mathrm{C}_{9}$ formula was calculated on the assumption of pure lignin. The number of methoxyl group per $\mathrm{C}_{9}$ unit in okra fibre and okra stick's lignin was 1.49 and 1.24 , respectively. The lower methoxyl group content of okra stick lignin indicates the lower content

Table II. Elemental analyses, methoxyl contents and per- $\mathrm{C}_{9}$-unit formula of okra fibre and stick lignin

\begin{tabular}{|c|c|c|c|c|c|}
\hline \multirow{2}{*}{$\begin{array}{l}\text { Lignin } \\
\text { sample }\end{array}$} & \multicolumn{4}{|c|}{ Elemental analysis, \% } & \multirow[t]{2}{*}{ C 9 formula } \\
\hline & $\mathrm{C}$ & $\mathrm{H}$ & $\mathrm{O}$ & $\mathrm{OCH} 3$ & \\
\hline Okra stick & 53.50 & 5.75 & 40.75 & 16.61 & $\mathrm{C}_{9} \mathrm{H}_{9.61} \mathrm{O}_{4.63}\left(\mathrm{OCH}_{3}\right)_{1.24}$ \\
\hline Okra fibre & 53.02 & 5.51 & 41.47 & 19.48 & $\mathrm{C}_{9} \mathrm{H}_{8.61} \mathrm{O}_{4.66}\left(\mathrm{OCH}_{3}\right)_{1.49}$ \\
\hline
\end{tabular}

Table III. Assignment of FTIR spectra of lignin from okra fibre and stick.

\begin{tabular}{|c|c|c|c|}
\hline $\begin{array}{l}\text { Peak } \\
\text { location } \\
\text { range } \mathrm{cm}^{-1}\end{array}$ & Assignment & Okra fibre & Okra stick \\
\hline $3412-3460$ & $\mathrm{O}-\mathrm{H}$ stretching & 3421.7 & 3425.3 \\
\hline $3000-2842$ & $\mathrm{C}-\mathrm{H}$ stretch in methyl and methylene group & 2936.7 & 29.39 .2 \\
\hline $1738-1709$ & $\begin{array}{l}\mathrm{C}=\mathrm{O} \text { stretch in unconjugated ketone, carbonyl and ester } \\
\text { groups }\end{array}$ & 1720.5 & 1712.5 \\
\hline $1675-1655$ & $\mathrm{C}=\mathrm{O}$ stretching in comjugated $\mathrm{p} \quad$-subst. Aryl ketones & 1670.4 & 1667.8 \\
\hline $1593-1605$ & $\begin{array}{l}\text { Aromatic skeleton vibrations plus } \mathrm{C}=\mathrm{O} \text { stretching; } \mathrm{S}>\mathrm{G} \text { : } \\
\mathrm{G}_{\text {condensed }}>\mathrm{G} \text { etherified }\end{array}$ & 1593.2 & 1604.7 \\
\hline $1505-1515$ & Aromatic skeleton vibrations $(\mathrm{G}>\mathrm{S})$ & 1504.5 & 1512.9 \\
\hline $1460-1470$ & $\mathrm{C}-\mathrm{H}$ deformations (asym in $-\mathrm{CH}_{3}$ and $-\mathrm{CH}_{2}-$ ) & 1462.0 & 1462.0 \\
\hline $1422-1430$ & $\begin{array}{l}\text { Aromatic skeleton vibrations combined with } \mathrm{C} \quad-\mathrm{H} \text { in plane } \\
\text { deformations }\end{array}$ & 1423.5 & 1423.5 \\
\hline $1365-1370$ & Aliphitic $\mathrm{C}-\mathrm{H}$ stretching in $\mathrm{CH}_{3}$ and phen. $\mathrm{OH}$ & - & \\
\hline $1325-1330$ & Condensed $\mathrm{S}$ and $\mathrm{G}$ ring ( $\mathrm{G}$ ring bound via position 5 ) & 1327.0 & 1328.9 \\
\hline $1266-1270$ & $\mathrm{G}$ ring plus $\mathrm{C}+\mathrm{O}$ stretching & - & \\
\hline $1221-1230$ & $\mathrm{C}-\mathrm{C}+\mathrm{C}-\mathrm{O}+\mathrm{C}=\mathrm{O}$ stretching $\left(\mathrm{G}_{\text {condensed }}>\mathrm{G}_{\text {etherified }}\right)$ & 1222.9 & 1219.2 \\
\hline 1166 & Typical for HGS lignins; $\mathrm{C}=\mathrm{O}$ in ester groups (conj.) & & \\
\hline 1140 & $\begin{array}{l}\text { Aromatic } \mathrm{C}-\mathrm{H} \text { in -plane deformation (typical of } \mathrm{G} \text { unit; } \\
\mathrm{G}_{\text {condensed }>\mathrm{G} \text { etherified) }}\end{array}$ & & \\
\hline $\begin{array}{l}1125-1128 \\
1086\end{array}$ & $\begin{array}{l}\text { Typical of S unit; also secondary alcohol \& } \mathrm{C}=\mathrm{O} \text { strt. } \\
\mathrm{C}-\mathrm{O} \text { deformation in sec. alcohol \& aliphatic ether }\end{array}$ & 1120.6 & 1116.8 \\
\hline $1030-1035$ & $\begin{array}{l}\text { Aromatic } \mathrm{C}-\mathrm{H} \text { in - plane deformation }(\mathrm{G}>\mathrm{S}) \text { plus } \mathrm{C}-\mathrm{O} \text { deform. } \\
\text { in primary alcohols plus } \mathrm{C} \quad-\mathrm{H} \text { stretching (unconjugated) } \\
-\mathrm{HC}=\mathrm{CH} \text { - out of plane deformation. (trans) }\end{array}$ & 1028.6 & 1033.9 \\
\hline $966-990$ & $\mathrm{C}-\mathrm{H}$ out of plane (aromatic ring) & & \\
\hline $915-925$ & $\mathrm{C}-\mathrm{H}$ out of plane in positions 2,5 and 6 (G units) & & 918.0 \\
\hline $853-858$ & $\mathrm{C}-\mathrm{H}$ out of plane in positions 2 and 6 of S units & & \\
\hline $834-835$ & $\mathrm{C}-\mathrm{H}$ out of plane in positions 2,5 and 6 of $\mathrm{G}$ units & 833.5 & 833.4 \\
\hline $817-832$ & & & \\
\hline
\end{tabular}


of syringyl type structure than that of okra fibre's lignin, which is close to the methoxyl content in cotton stalk's lignin and the lignin present in dhaincha respectively (Jahan et al., 2007a). Similar differences of lignin in jute stick and fibre was also found elsewhere (Islam and Sarkanen, 1993). The methoxyl content in okra fibre lignin and okra stick lignin was very similar to temperate hardwood (aspen) lignin and tropical hardwood (T. orientalis) lignin, respectively (Jahan and Mun, 2010). band at $1600 \mathrm{~cm}^{-1}$ is assigned to the aromatic skeletal vibrations, $1510 \mathrm{~cm}^{-1}$ assignd to the aromatic skeletal vibrations coupled with $\mathrm{C}-\mathrm{H}$ in plane deformations, 1460 $\mathrm{cm}^{-1}$ assigned to $\mathrm{C}-\mathrm{H}$ deformations (asymmetric in methyl, methylene and methoxyl group. Both lignins showed stronger bands for syringyl unit than the guaiacyl units. The band intensity at $1327 \mathrm{~cm}^{-1}, 1122 \mathrm{~cm}^{-1}$ and $833 \mathrm{~cm}^{-1}$ for syringyl unit was higher in fiber lignin than in the okra stick lignin, while band at $1270 \mathrm{~cm}^{-1}, 1041 \mathrm{~cm}^{-1}$ and $918 \mathrm{~cm}^{-1}$ for guaiacyl units in okra stick lignin was stronger than fiber lignin. The results indicated the presence of both guaiacyl

\section{Table IV. Assignments of signal and protons per $\mathrm{C}_{9}$ structural unit in the ${ }^{1} \mathrm{H}$ NMR spectra of acetylated lignins of okra fibre and stick}

\begin{tabular}{|c|c|c|c|}
\hline Range ppm & Main assignments & Okra stick & Okra fibre \\
\hline $7.25-6.80$ & $\begin{array}{l}\text { Aromatic proton in } \\
\text { guaiacyl units }\end{array}$ & 0.45 & 0.31 \\
\hline $6.80-6.25$ & $\begin{array}{l}\text { Aromatic proton in } \\
\text { syringyl units }\end{array}$ & 0.70 & 0.98 \\
\hline $6.25-5.75$ & $\begin{array}{l}\text { H } \alpha \text { of } \beta-O-4 \text { and } \beta-1 \\
\text { structures }\end{array}$ & 0.35 & 0.34 \\
\hline $5.75-5.24$ & H $\alpha$ of $\beta-5$ structure & 0.56 & 0.30 \\
\hline $5.20-4.90$ & $\mathrm{H}$ of xylan residue & & \\
\hline $4.90-4.30$ & $\begin{array}{l}\mathrm{H} \alpha \& \mathrm{H} \beta \text { of } \beta-O-4 \\
\text { structures }\end{array}$ & 1.53 & 1.20 \\
\hline $4.30-4.00$ & $\begin{array}{l}\text { H } \alpha \text { of } \beta-\beta \text { structures } \\
\text { H of xylan residue }\end{array}$ & - & - \\
\hline $4.00-3.48$ & H of methoxyl groups & 3.72 & 4.47 \\
\hline $2.50-2.22$ & $\mathrm{H}$ of aromatic acetates & 1.24 & 0.64 \\
\hline $2.22-1.60$ & $\mathrm{H}$ of aliphatic acetates & 2.38 & 4.55 \\
\hline
\end{tabular}

\section{FTIR Spectra}

To elucidate the structure of lignin, and investigate the differences in the structure of the dioxane lignin isolated from okra stick and fibre, FT-IR spectra were recorded and shown in Fig. 1. The assignment made by Faix (1991) is given in Table III. The ester carbonyl signal at $1714 \mathrm{~cm}^{-1}$ together and the band at $833 \mathrm{~cm}^{-1}$ suggests the presence of esterified $p$-coumaric units in okra fiber and stick lignin (Faix 1991), which are common in nonwood lignin (Seca et al., 1998). The and syringyl unit in the lignin molecule, but the syringyl unit in fibre lignin was higher than in the stick lignin. The result is consistent with the elemental analysis data.

\section{${ }^{1} H N M R$}

The integrated NMR spectrum obtained for acetylated okra fibre and okra stick lignin is shown in Fig. 2. Table IV lists the position of signal assigned by Lundquist (1992). Hydroxyl group: The numbers of free aliphatic and 


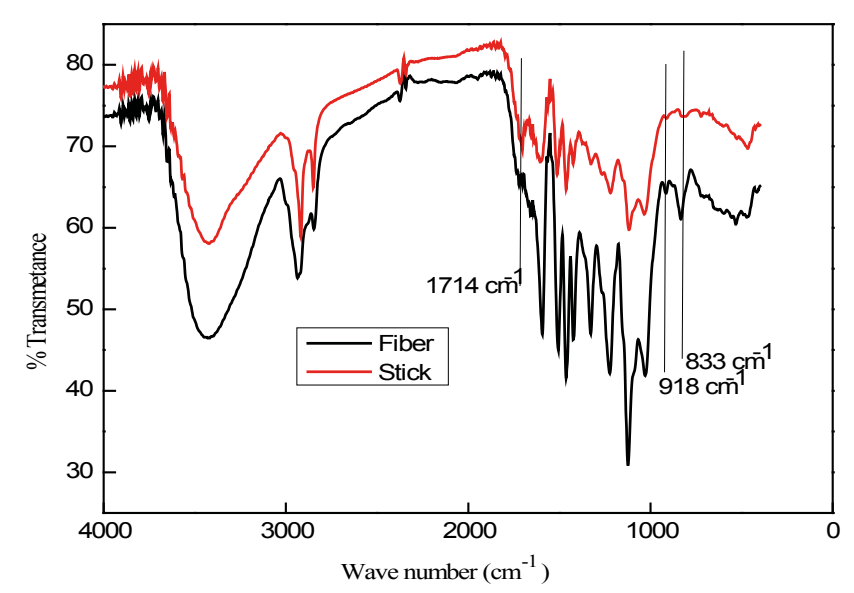

Fig. 1. FT-IR spectra of lignin isolated from okra fibre and okra stick

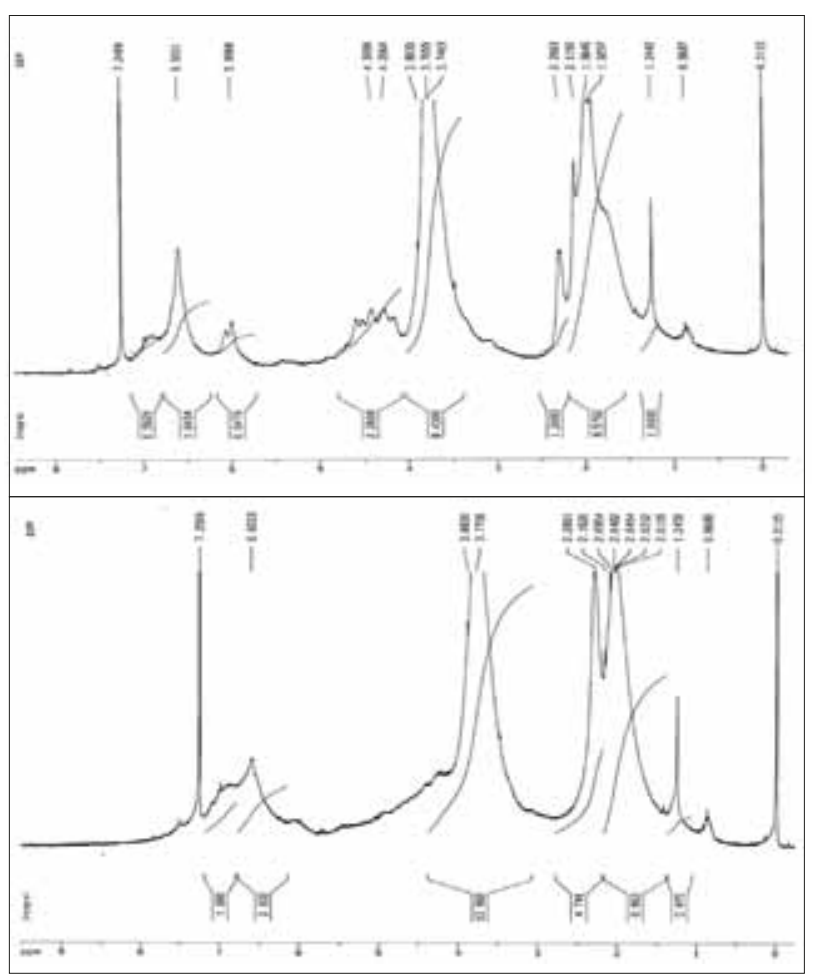

Fig. 2. FT-IR spectra of lignin isolated from okra fibre (top) and okra stick (bottom).

phenolic hydroxyl groups per $\mathrm{C}_{9}$ unit were determined from the corresponding acetate signals. The numbers of proton per $\mathrm{C}_{9}$ unit of phenolic hydroxyl group of okra stick and okra fibre lignin were 1.24 and 0.64 , respectively. The proton of aliphatic hydroxyl group per $\mathrm{C}_{9}$ unit was 2.38 and 4.55 for okra stick and fibre, respectively. It would expect that less aromatic and aliphatic $\mathrm{OH}$ for high molecular weight lignin.
Aromatic protons: Okra stick and okra fibre lignin spectra show two peaks in the aromatic proton region, which correspond to guaiacyl units $(\delta 6.9)$ and syringyl units $(\delta 6.6)$. Both lignins show stronger peak in syringyl units region $(\delta$ 6.6) than that of guaiacyl units region ( $\delta$ 6.9) (Fig. 3). But stick lignin has higher guaiacyl peak than the corresponding fibre lignin. NMR integration shows that okra stick lignin contains 0.45 guaiacyl proton and 0.70 syringyl proton per $\mathrm{C}_{9}$ units, while these are 0.31 and 0.98 for okra fibre lignin, respectively (Table IV), which suggests highly condensed lignins. Presence of lower amount of aromatic proton suggests the presence of p-coumaryl units. The result is in good agreement with the results of empirical formula and FTIR spectra (Table II).

$\beta-\mathrm{O}-4$ structure: The aryl glycerol $\beta-\mathrm{O}-4$ aryl ether linkage constitute the main intermonomeric connection in lignin (Lundquist 1992). NMR spectra of lignin of cotton stalks, jute stick and dhancha show that the structural element may contain both erythro and threo configurations due to the presence of proton at the $\mathrm{C}-\alpha$ position of the side chain. The erythro protons $(\mathrm{H} \alpha)$ give stronger peak at $\delta 6.01$ than the peak for thero form at $\delta 6.09$ in okra fibre lignin. Akiyama et $a l$. , (2003) reported that the angiousperms lignin contains higher erythro form in $\beta-\mathrm{O}-4$ units than thero form. The average numbers of protons per $\mathrm{C}_{9}\left(\mathrm{H}_{\alpha} \& \mathrm{H}_{\beta}\right)$ of $\beta-\mathrm{O}-4$ in okra stick and fibre lignins were 1.53 and 1.20 , respectively. The broad signal around $7.6 \mathrm{ppm}$ was assigned to H-2/H-6 aromatic protons and $\mathrm{H} \alpha$ in p-coumaric acid structures (Ralph et al., 1996), confirming their significant amounts in okra fibre and stick lignin.

\section{Conclusion}

The lignins isolated from the okra fibre and sticks are mainly composed with syringyl unit and guaiacyl unit. Okra fibre lignin contains higher syringyl unit compared with stick lignin. The $\mathrm{OCH}_{3} / \mathrm{C}_{9}$ is 1.49 for okra fibre lignin and 1.24 for stick lignin. From the ${ }^{1} \mathrm{H}$ NMR spectra, the number of proton of phenolic and aliphatic hydroxyl group were estimated to be 0.41 and 0.79 for okra stick lignin and 0.21 and 1.51 for okra fibre per $\mathrm{C}_{9}$ unit, respectively. ${ }^{1} \mathrm{H}$ NMR study showed that the $\beta-\mathrm{O}-4$ structural unit is higher for lignin of stick. Both lignins contain both erythro and threo configuration, but erythro proportion was higher. Overall the results of this investigation indicate that the okra plant lignin is of guaiacyl-syringyl and significant amount of $p$-coumaryl type.

\section{Acknowledgement}

Authors wish to thank BCSIR authority to provide fund to carry out the research. 


\section{References}

Akiyama T, Matsumoto Y, Okuyama T and Meshitsuka G (2003), Ratio of erythro and thero form of $\beta-O-4$ structure in tension wood lignin, Phytochemistry 64: 1157-1162.

Björkman A (1957), Lignin and lignin-carbohydrate complexes -extraction from wood meal with neutral solvents, Ind. Eng. Chem. 49: 1395-1398.

Eriksson Ö, Goring D and Lindgren B O (1980), Structural studies on the chemical bonds between lignins and carbohydrates in spruce wood, Wood Sci. Technol. 14: 267-279.

Faix O (1991), Classification of lignins from different botanical origins by FTIR spectroscopy, Holzforschung 45: 21-28.

Fengel D and Wegener G (1989), In: Wood Chemistry, Ultrastructure and Reactions, Ed. Walter de Gruyter, Berlin pp 613.

Gellerstedt G, Pranda J and Lindfors EL (1994), Structural and Molecular Properties of Residual Birch Kraft Lignins, J. Wood Chem. Technol. 14(4): 467-482.

Islam A and Sarkanen KV (1993), The Isolation and Characterization of the Lignins of Jute (Corchorus capsularis), Holzforschung 47: 123-132.

Jahan MS, Maruf AA and Quaiyyum MA (2007), Comparative studies of pulping of jute fiber, jute cutting and jute caddis, Bangladesh J. Sci. Ind. Res. 42(4): 425-434.

Jahan MS, Chowdhury DAN, Islam MK and Moeiz SM (2007a), Characterization of lignin isolated from some nonwood available in Bangladesh Bioresource technology 98(2): 465-469.

Jahan MS and Mun SP (2010), Isolation and Characterization of lignin from tropical and temperate hardwood, Bangladesh, J. Sci. Ind. Res. 44(3): 271-280.

Jahan MS, Kanna GH, Mun SP \& Chowdhury DN (2008), Variations in Chemical Characteristics and Pulpability within Jute Plant (Chorcorus capsularis), Ind. Crops Prod. 28: 199-205.

Jahan MS, Rahman M and Rahman MM (2012), Characterization and evaluation of okra fibre (abelmoschus esculentus) as a pulping raw material, J-For. 2(5): 12-17.
Lowoko M (2003), New method for quantitative preparation of lignin-carbohydrate complex from unbleached softwood kraft pulp. Lignin-polysaccharide networks I, Holzforschung 57: 69-74.

Lundquist K (1992), Proton NMR spectroscopy In: Methods in Lignin Chemistry, Eds. Lin SY and Dence CW, Springer, Heidelberg pp 242-249.

Ralph J, Marita J, Ralph S, Hatfield R, Lu F, Ede R, Peng J, Quideau S, Helm R, Grabber J, Kim H, Jimenez-Monteon G, Zhang Y, Jung H, Landucci L, Mackay J, Sederoff R, Chapple C and Boudet A (2000), Solution-state NMR of lignins. In: Advances in Lignocellulosic Characterization, Eds. Argyropoulos D and Rials T, TAPPI Press: Atlanta pp 55-108.

Ralph SA, Ralph J and Landucci LL (1996), NMR Database of Lignin and Cell Wall Model Compounds, available at URL http://www.dfrc.wisc.edu/software.html.

Seca A, Cavaleiro J, Domingues F, Silvestre, A, Evtuguin D and Neto PC (1998), Structural characterisation of the bark and core lignins from kenaf (Hibiscus cannabinus), J. Agric. Food Chem. 46: 3100-3108.

Tamminen TL and Hortling BR (1999), Isolation and characterization of residual lignin In: Advances in Lignocellulosics Characterization, Ed. Argyropoulos DS, Tappi Press, Atlanta Chapter 1, pp 1-4.

Yaku F, Yamada $\mathrm{Y}$ and Koshijima T (1981), Lignin-carbohydrate complex. Part IV. Lignin as a side chain of the carbohydrate in Björkman LCC, Holzforschung 35(4): 177-181.

Yaku F, Yamada Y and Koshijima T (1976), Lignin carbohydrate complex Part II. Enzymic degradation of acidic polysaccharide in Björkman LCC, Holzforschung 30: 148-156.

Received: 25 August 2015; Revised: 31 August 2015;

Accepted: 19 October 2015 